\title{
RELAÇÕES CONTRATUAIS DE CRÉDITO AGRÍCOLA E O PAPEL DOS AGENTES FINANCEIROS PRIVADOS: TEORIA E EVIDÊNCIAS DOS EUA*
}

Fabio R. Chaddad Sérgio G. Lazzarini

Abstract: Este trabalho analisa a questão do financiamento da produção agrícola sob uma ótica sistêmica, considerando o papel dos agentes privados no fornecimento de crédito rural. Desenvolve-se a idéia de que o volume e o custo de recursos financeiros disponibilizados para a produção agrícola são afetados por "fricções" em diversas transações sequenciais interligando emprestadores e tomadores de crédito. $\mathrm{O}$ objetivo do trabalho é analisar as vantagens comparativas dos diversos agentes que atuam no mercado de crédito, enfocando o potencial de cada agente em reduzir as tais fricções. Esta análise comparativa baseia-se na leitura do funcionamento do mercado de crédito agrícola dos Estados Unidos e pode ser aplicada nara o desenvolvimento de novos arranjos contratuais no mercado brasileiro.

Palavras-chave: crédito agrícola, mercado de crédito, contratos, agribusiness.

\section{Introdução}

Tradicionalmente, as discussões sobre o financiamento da produção agrícola têm sido focadas na interface entre agentes financeiros e produtores, e políticas públicas direcionadas a tal questão têm enfatizado o papel do governo no fornecimento de recursos e na regulamentação da atividade bancária visando aumentar a oferta de crédito. Apesar deste enfoque ter contribuído para o entendimento

\footnotetext{
* Agradecemos os comentários de três pareceristas anônimos e o estímulo de Paulo Faveret Filho (BNDES) para perseguir esta linha de pesquisa. Erros e omissões restantes são de nossa inteira responsabilidade.
} 
sobre o financiamento da atividade agrícola, a análise isolada da transação entre agentes financeiros e produtores necessariamente ignora o papel de várias transações simultâneas e articuladas com o processo de transferência de crédito que ocorrem no âmbito dos sistemas agroindustriais (SAGs). Por exemplo, a obtenção de crédito para a compra de fertilizantes envolve um terceiro agente no processo, o fornecedor de insumos, cuja atuação não somente afeta a adoção de tecnologia por parte do produtor, mas também os seus incentivos em honrar o contrato de crédito. Assim, a presença do fornecedor de insumos pode resultar em maior oferta de crédito caso os intermediários financeiros se utilizarem deste agente como fonte de informações ou como meio de salvaguardar contratos.

Este artigo propõe que a questão do financiamento da produção agrícola deve ser analisada sob uma ótica sistêmica, considerando o papel dos diversos agentes privados do agribusiness no fornecimento de crédito agrícola. Em particular, desenvolve-se a idéia de que o volume e o custo de recursos financeiros disponibilizados para a produção agrícola dependem não somente das taxas de juros incidentes no momento da captação de tais recursos, mas também de "fricções" em diversas transações sequenciais interligando emprestadores e tomadores de crédito. Tais fricções devem-se aos custos de informação e custos de transação característicos de relações contratuais, incluindo os contratos de crédito. Fricções contratuais são particularmente pronunciadas no mercado agrícola em função da dispersão geográfica de produtores, a qual dificulta o processo de coleta de informações e monitoramento de contratos. A necessidade de uma visão sistêmica deste processo se justifica porque produtores agrícolas estão cada vez mais se relacionando contratualmente com empresas à jusante e montante nos SAGs (Cook \& Chaddad, 2000). Uma vez que tais empresas fornecem contratos de crédito e têm em muitos casos maiores capacitações de fazer cumprir tais contratos, podem reduzir certos tipos de fricções e por conseguinte aumentar a oferta de crédito (Lazzarini, 1998).

Partindo-se desta idéia central, este artigo tem o objetivo de analisar as vantagens comparativas dos diversos agentes que atuam 
no mercado de crédito agrícola, enfocando o potencial de cada agente em reduzir as fricções que ocorrem nos contratos de fornecimento de crédito a produtores agrícolas. Esta análise comparativa baseia-se na leitura do funcionamento do mercado de crédito agrícola dos EUA, o qual se caracteriza por uma miríade de agentes privados. Apesar dos mercados financeiros serem altamente desenvolvidos naquele país, certos agentes privados - tais como cooperativas, tradings e agroindústrias - têm participação marcante no financiamento da produção agrícola. Contrário ao senso comum, o governo federal americano tem participação direta muito restrita neste mercado, ofertando uma pequena parcela do total da dívida agrícola (USDA, 2003). Com base na experiência norte-americana, demonstra-se que a análise do papel destes agentes é fundamental para o entendimento do processo de transferência de crédito e de que forma sua eficiência pode ser aumentada.

O trabalho está organizado em quatro partes. Primeiramente, desenvolve-se o arcabouço conceitual sobre fricções em contratos de crédito agrícola. Na seqüência, abordam-se aspectos institucionais e organizacionais do mercado de crédito agrícola norte-americano. A partir da experiência norte-americana, é feita uma análise comparativa entre bancos comerciais, cooperativas de crédito, empresas privadas que atuam nos SAGs e programas governamentais na oferta de crédito. Comentários finais encerram o trabalho.

\section{Fricções nos Contratos de Crédito}

Nesta seção, baseada em Lazzarini \& Chaddad (2000), apresentam-se conceitos teóricos que enfatizam o papel das fricções no mercado de crédito. Tais fricções causam uma disparidade entre a taxa de juros recebida pelo intermediário financeiro (emprestador) e a taxa de juros cobrada do tomador de crédito. Apesar das discussões sobre crédito agrícola geralmente enfatizarem as taxas de juros pagas por diversos intermediários financeiros, a parcela correspondente às fricções pode ser, em muitos casos, bastante expressiva. Logo, existe espaço para ações voltadas à redução destas fricções a fim de se reduzir 
os juros efetivamente pagos pelos produtores - mesmo porque a taxa recebida pelo emprestador tende a ser ditada por taxas de juros de mercado, por sua vez influenciadas por políticas macroeconômicas fora do controle dos agentes privados. Enfatizam-se, a seguir, duas grandes fontes de fricções nos contratos de crédito: os custos de informação e os custos de transação.

\subsection{Custos de Informação}

É comum na literatura caracterizar a relação contratual entre o emprestador e o tomador de crédito como uma relação de agenteprincipal com informação assimétrica (Ross, 1973; Stiglitz, 1974; Myers and Majluf, 1984; Hoff \& Stiglitz, 1993; Barry, Bierlen \& Sotomayor, 2000). Neste sentido, dois problemas contratuais podem surgir. Sob uma ótica pré-contratual, o tomador de crédito possui informações que o emprestador não tem e, em vista disso, pode ocultar informações com o objetivo de aumentar sua chance de receber o crédito. Stiglitz \& Weiss (1981) demonstram que, ao aumentar a taxa de juros em condições de assimetria informacional, o intermediário financeiro acaba atraindo investidores de maior risco, pois neste caso somente projetos de investimento com retorno de maior variância mantêm-se com valor presente líquido positivo - um caso particular do que é conhecido na literatura como seleção adversa (Akerlof, 1970). Em conseqüência, o emprestador não aumenta necessariamente o retorno esperado de sua carteira de crédito. Surge, então, o fenômeno de racionamento de crédito, pois o emprestador tende a não oferecer crédito a indivíduos de maior risco.

Outra forma de oportunismo se dá após o fechamento do contrato, quando o tomador altera seu comportamento e toma ações que aumentam seu risco de inadimplência. Este caso é conhecido na literatura como risco moral (Arrow, 1971). Por exemplo, quando o tomador aumenta sua taxa de endividamento, os custos que recaem sobre o emprestador em caso de inadimplência tendem a aumentar. $\mathrm{O}$ risco moral é agravado na relação de crédito devido à nãoespecificidade e fungibilidade do dinheiro, isto é, uma vez consumado 
o empréstimo, o tomador pode utilizar o recurso financeiro de acordo com suas preferências.

Em ambos os casos, o emprestador tem que efetivamente gastar recursos - denominados custos de informação (Stiglitz, 2000) - para levantar informações acerca do perfil do potencial tomador e avaliar seu risco de crédito. Na prática, o levantamento de informações é feito por meio de uma análise do histórico do tomador em empréstimos anteriores, dados contábeis, indicadores financeiros e, especialmente no mercado agrícola, uma análise do perfil tecnológico do produtor. Entretanto, este tipo de ação é imperfeita, porque agentes oportunistas têm incentivos para formar reputação no mercado, "imitando" a ação de agentes honestos. Isto ocorre quando tomadores oportunistas desejam obter crédito por um longo período no futuro. Entretanto, quando tais agentes não mais desejam obter crédito, os incentivos gerados por reputação diminuem, aumentando o risco de que o contrato não será mais cumprido (Kreps et al., 1982). Assim, tornam-se necessários mecanismos mais complexos de incentivo ao cumprimento do contrato de crédito. A necessidade de tais mecanismos gera custos de transação que incidem sobre o processo de financiamento, os quais são discutidos a seguir.

\subsection{Custo de Transação Pré-Contratuais}

Em uma fase pré-contratual, o emprestador pode se sujeitar a diversas fontes de custos de transação. Considere os custos de negociação. Primeiramente, existem custos para "juntar" potenciais emprestadores e tomadores. Além disso, dado que o tomador não tem informação completa a respeito da taxa de captação do emprestador, e o emprestador não tem informação completa da capacidade do tomador em honrar a dívida, as partes terão dificuldades em avaliar os ganhos envolvidos na troca (Myerson \& Satterthwaite, 1983). Ademais, uma vez que o processo de tomada de crédito geralmente é realizado por um intermediário financeiro, os custos de negociação também podem embutir comissões a este agente.

A necessidade de salvaguardas introduz custos adicionais no contrato de crédito (Williamson, 1985). Salvaguardas contratuais são 
mecanismos de compensação ao emprestador caso o tomador tornese inadimplente, incluindo-se colaterais dos mais diversos tipos, mecanismos de aval e fiança, e ajustes em exigências de pagamento inicial, maturidade do empréstimo e cláusulas contratuais que limitam a capacidade do tomador de contrair novas dívidas.

Custos de transação pré-contratuais adicionais podem surgir devido ao uso de mecanismos de incentivos, que visam induzir o tomador a realizar ações que diminuem sua probabilidade de inadimplência (Sappington, 1991). Um tipo de incentivo bastante comum é a exigência de que o produtor realize hedging em mercados futuros ou por meio de contratos a termo com um comprador a fim de se reduzir a probabilidade de inadimplência do tomador em função de uma variação adversa de preços. Da mesma forma, exigências de seguro agrícola são normalmente associadas a contratos de crédito para se controlar riscos de produção devido a fatores climáticos. Quando o crédito é fornecido por empresas de insumos ou processadores, o financiamento pode também embutir um processo de transferência tecnológica que reduz o risco de inadimplência por aumentar o desempenho técnico-econômico do produtor. Adicionalmente, o emprestador pode efetuar uma transferência de renda para o tomador, por exemplo cobrando uma taxa de juros mais baixa ou preços privilegiados para a aquisição ou venda de produtos, quando o crédito for fornecido por empresas não-financeiras (Hoff \& Stiglitz, 1993). Tal transferência de renda pode favorecer o cumprimento do contrato porque, sob a ótica do tomador, a manutenção do crédito sob um longo período de tempo é vista como uma alternativa mais lucrativa do que uma ação lesiva de curto prazo, o que causaria uma retaliação por parte do emprestador (Klein, 1996).

\subsection{Custo de Transação Pós-Contratuais}

Os custos de transação incorridos em uma fase pós-contratual decorrem do fato de que os mecanismos de controle do risco de inadimplência em uma fase pré-contratual tendem a ser imperfeitos. Além de serem custosos, tais mecanismos pré-contratuais tendem a 
ser extremamente complexos, dadas as dificuldades de se prever contingências futuras. Sendo assim, emprestadores passam a despender recursos em ações de monitoramento e controle em uma fase póscontratual para verificar o uso dos recursos emprestados e acompanhar o desempenho financeiro dos tomadores de forma a detectar possíveis "candidatos" a inadimplência. Se indivíduos com uma alta probabilidade de inadimplência forem detectados, recursos adicionais podem ser gastos na renegociação de cláusulas contratuais. Finalmente, se todos estes mecanismos pré- e pós-contratuais falharem, surgirão custos de má-adaptação contratual (Williamson, 1996). Mais especificamente, pode existir um nível de inadimplência "irremediável" cuja prevenção pode ser técnica ou economicamente inviável. A inadimplência "irremediável" traz como consequiência custos de receber e vender colaterais, despesas com litígio e possíveis impactos negativos sobre o fluxo de caixa do emprestador.

Com base nestes conceitos teóricos, na próxima seção são apresentadas evidências de como se dá o processo de financiamento agrícola nos EUA. A seção subseqüente utiliza tais evidências para discutir de que forma os agentes envolvidos no mercado de crédito agrícola têm vantagens comparativas distintas para dirimir cada tipo de fricção nos contratos de transferência de crédito.

\section{O Financiamento da Produção Agrícola nos EUA ${ }^{1}$}

A experiência dos EUA com relação ao fluxo de capitais nos SAGs revela a importância dos agentes privados no financiamento da produção agrícola. Ao final de 2002, o total da dívida agrícola atingiu cerca de US\$202 bilhões, o maior nível desde 1985. O fato importante a ser enfatizado nesta seção é que $96,5 \%$ do total da dívida agrícola nos EUA, o equivalente a US\$195 bilhões, é oriundo de agentes privados (veja a Tabela 1). Dentre tais agentes privados, destacam-se os bancos comerciais, com $40 \%$ de participação de mercado, o sistema de crédito agrícola cooperativo (30\%), as empresas privadas atuando

\footnotetext{
${ }^{1}$ Os dados estatísticos utilizados nesta seção foram obtidos de um relatório publicado pelo Departamento de Agricultura dos Estados Unidos (USDA, 2003).
} 
nos SAGs (21\%) e empresas de seguro de vida (6\%). Neste mercado, o governo federal tem participação direta muito restrita, ofertando somente 3,5\% do total da dívida agrícola - embora, como se destaca posteriormente, o governo tenha uma participação indireta importante por meio de programas de estabilização de renda e seguro, por exemplo. A seguir é feita uma análise do papel destes agentes atuando no mercado de crédito agrícola.

Tabela 1: Dívida Agrícola nos EUA por Emprestador, 1980-2002

\begin{tabular}{|c|c|c|c|c|c|c|c|c|c|c|c|c|}
\hline & \multicolumn{3}{c}{$\begin{array}{c}\text { Bancos } \\
\text { Comerciais }\end{array}$} & \multicolumn{2}{c}{$\begin{array}{c}\text { FCS } \\
\text { (Cooperativas) }\end{array}$} & \multicolumn{2}{c}{$\begin{array}{c}\text { Indivíduos } \\
\text { e Outros }\end{array}$} & \multicolumn{2}{c|}{$\begin{array}{c}\text { Cias. de Seguro } \\
\text { de Vida }\end{array}$} & \multicolumn{2}{c|}{$\begin{array}{c}\text { FSA } \\
\text { (Governo) }\end{array}$} \\
\hline \hline 1980 & 166,823 & 37,751 & 22.63 & 52,974 & 31.75 & 46,636 & 27.96 & 11,998 & 7.19 & 17,464 & 10.47 \\
1985 & 177,599 & 44,470 & 25.04 & 56,169 & 31.63 & 41,152 & 23.17 & 11,273 & 6.35 & 24,535 & 13.81 \\
1990 & 137,963 & 47,556 & 34.47 & 35,773 & 25.93 & 27,916 & 20.23 & 9,704 & 7.03 & 17,014 & 12.33 \\
1995 & 150,770 & 60,025 & 39.81 & 37,324 & 24.76 & 34,182 & 22.67 & 9,092 & 6.03 & 10,147 & 6.73 \\
2002 & 201,894 & 79,529 & 39.39 & 61,191 & 30.31 & 41,820 & 20.71 & 12,287 & 6.09 & 7,067 & 3.50 \\
\hline
\end{tabular}

Fonte USDA (2003)

\subsection{Bancos Comerciais}

Os bancos comerciais desempenham um papel fundamental na oferta de crédito e serviços financeiros para a agricultura americana. O montante de crédito disponibilizado por bancos comerciais passou a marca de US $\$ 80$ bilhões em 2002, o equivalente a $40 \%$ do mercado. Deste total, US $\$ 45$ bilhões referem-se a empréstimos de curto e médio prazo, ao passo que os US\$35 bilhões restantes são empréstimos de longo prazo. A participação dos bancos comerciais na oferta de crédito agrícola tem crescido desde a crise da dívida agrícola ocorrida em meados da década de 1980.

Uma análise dos dados financeiros de todos os bancos comerciais assegurados pela Federal Deposit Insurance Corporation (FDIC), órgão federal que regulamenta o setor, revela que estão ocorrendo mudanças estruturais importantes no financiamento da agricultura americana por esses agentes. Por exemplo, durante a década de 1960, os bancos de 
pequeno porte eram responsáveis por cerca de $70 \%$ do total de empréstimos agrícolas por bancos comerciais. Dados mais recentes mostram que o número desses pequenos bancos rurais caiu significativamente e sua participação de mercado despencou para menos de 5\% em 1999. Ou seja, os bancos comerciais de maior porte estão aumentando sua atuação no mercado de crédito agrícola. Além disso, muitos bancos comerciais considerados como não-agrícolas - com menos de $16 \%$ de seus ativos investidos em empréstimos ao setor agrícola - tornaram-se importantes fornecedores de crédito rural. Em outras palavras, os bancos agrícolas tradicionais estão perdendo mercado para bancos de maior porte, com uma carteira de investimentos mais diversificada, com maior acesso ao mercado de capitais, e com capacidade de financiar a demanda de crédito e serviços financeiros por agricultores de grande porte.

A principal fonte de recursos dos bancos comerciais são depósitos em conta corrente, os quais determinam a sua capacidade de empréstimo. Além dos depósitos em conta corrente, os bancos comerciais contam com capital próprio, retenção de lucros e emissão de títulos e debêntures em mercados financeiros como fontes alternativas de capital. De um modo geral, os bancos comerciais são empresas altamente alavancadas, com capital próprio entre 5 a $10 \%$ do total dos ativos. O recente crescimento da participação de mercado dos bancos de maior parte deve-se, em parte, à sua maior facilidade de acesso a fontes de capital de risco a custo relativamente mais baixo do que os pequenos bancos agrícolas.

\subsection{Sistema de Crédito Rural Cooperativo}

O sistema de crédito rural cooperativo (Farm Credit System ou FCS) é o segundo maior agente disponibilizando recursos financeiros para a agricultura americana. $\mathrm{O}$ volume de crédito oferecido pelas cooperativas de crédito rural passou a marca de US\$60 bilhões em 2002, representando 30\% de participação de mercado. O FCS é líder de mercado no crédito de longo prazo, sendo que a sua carteira de crédito com maturidade acima de 10 anos atingiu cerca de US $\$ 40$ bilhões em 2002. 
OFCS é uma fonte de crédito rural única na agricultura americana, um sistema que se espelhou na experiência européia com associações de crédito, mas com uma participação mais direta do governo. O seu papel é ser uma fonte segura de crédito para os agricultores americanos e manter as taxas de juros do mercado a níveis competitivos. Ou seja, o FCS foi criado e implementado para corrigir imperfeições no mercado de crédito rural no início do século passado (Cook, 1995). O FCS é um sistema de cooperativas de crédito organizado em uma estrutura federada (Lazzarini, Chaddad \& Cook, 2001). De acordo com esta estrutura, as cooperativas (ou associações) locais são responsáveis pelos empréstimos aos agricultores. Por definição, os membros (proprietários) das cooperativas locais são os próprios tomadores de crédito, que contribuem capital de risco e elegem o conselho de administração de suas associações. Por sua vez, as cooperativas locais são membros e obtêm seus recursos dos bancos cooperativos (cooperativas regionais). Além das associações locais e bancos cooperativos, o FCS é constituído pelo CoBank (banco especializado em ofertar crédito para as cooperativas agrícolas), Farm Credit System Leasing Corporation (que oferta leasing para máquinas e implementos agrícolas), Farm Credit System Funding Corporation (que emite títulos de dívida do sistema para captação de recursos nos mercados financeiros) e o órgão federal regulamentador (Farm Credit Administration).

O FCS foi institucionalizado através de uma série de leis do congresso americano entre 1916 e 1933. Uma importante restrição imposta pelos atos do congresso que estabeleceram o FCS é que as associações e bancos cooperativos são organizações financeiras nãodepositárias. Em outras palavras, elas não podem receber depósitos em conta corrente de seus clientes. A única fonte de capital de risco do FCS, além das contribuições dos próprios membros, são títulos de dívida do sistema emitidos em mercados financeiros. O FCS conta com uma organização especializada na captação de recursos do mercado, chamada Funding Corporation, que os repassa para os bancos cooperativos e estes para suas associações locais. Uma vantagem do FCS com relação aos bancos comerciais é que seus títulos de dívida e notas de desconto são implicitamente garantidos pelo 
tesouro americano. Logo, o risco e o prêmio dos títulos do FCS são menores que os emitidos pelos bancos comerciais. De modo geral, as taxas de juros oferecidas pelas associações locais do FCS a seus membros tendem a ser um pouco abaixo da concorrência. Outra vantagem competitiva das associações locais de crédito é que são isentas de impostos sobre o resíduo (lucro).

\subsection{Agentes Não-Financeiros dos Sistemas Agroindustriais}

Segundo dados do USDA (2003), a participação de agentes não-financeiros no financiamento da agricultura americana é substancial, ao redor de US\$42 bilhões ou $21 \%$ do mercado em 2002. Adicionalmente, a sua participação de mercado vem crescendo desde 1990. Entretando, os dados do USDA são agregados na categoria "indivíduos e outros", não nos permitindo ter uma estimativa do volume de crédito agrícola ofertado pelos diversos agentes privados.

Uma pesquisa de campo realizada por Sherrick et al. (1994) revela um aumento no volume e escopo dos programas de crédito por parte de empresas de insumos, processadores e cooperativas agrícolas, os quais foram denominados de "emprestadores não-tradicionais". A pesquisa incluiu duas cooperativas (Growmark e Farmland), dois produtores de sementes (Pioneer e DeKalb), um produtor de ração animal (Purina Mills) e dois produtores de máquinas e implementos (Deere \& Co. e Case). Somente estas empresas apresentaram volume de crédito ofertado na ordem de US\$6 bilhões. Entre 1988 e 1993, muitas destas empresas adicionaram crédito à sua linha de produtos ou expandiram o seu escopo, chegando em alguns casos a quadruplicar o volume de crédito fornecido.

De forma geral, a atuação dos agentes não-financeiros no mercado de crédito agrícola é mais pronunciada nos empréstimos de curto e médio prazo, ou seja, no financiamento da compra de insumos, máquinas e implementos. Neste mercado, a participacão das empresas agroindustriais e de insumos chega a US\$22 bilhões ou $25 \%$ do mercado, somente ficando atrás dos bancos comerciais. De acordo com Sherrick (1998), trata-se da segunda maior fonte de crédito 
operacional (custeio) para os agricultores comerciais norte-americanos, aqueles com receita anual bruta acima de US\$100 mil. Além disso, $60 \%$ do crédito agrícola de curto prazo de tais produtores tem origem nas empresas privadas atuando nos SAGs.

Do ponto de vista estratégico, muitos fatores são citados para explicar a existência e importância dos agentes privados do agribusiness como fonte de crédito agrícola. Primeiramente, empresas de insumos e fabricantes de máquinas e implementos decidem ofertar crédito no pontode-venda como estratégia de marketing, ou seja, como um serviço adicional visando aumentar as vendas e "fidelizar" os clientes. Esta prática tende a ser mais comum quando a empresa detém poder de mercado, porque pode oferecer crédito abaixo do custo para subsidiar a compra de produtos com margens elevadas (Sherrick \& Lubben, 1994). No caso das empresas agroindustriais e alimentares, a oferta de crédito a produtores agrícolas visa diminuir os riscos associados ao suprimento de matéria-prima, criando-se uma dependência bilateral com o produtor que aumenta a probabilidade de continuação contratual em safras futuras (Sherrick et al., 1994). Os "integradores", agentes importantes nos sistemas agroindustriais de suínos e frangos, também oferecem grande parte do capital de risco necessário para a implementação e/ou aumento da capacidade produtiva de seus integrados. Tal financiamento resulta na divisão de riscos entre o integrador e seus integrados, além de favorecer a transferência e proteção de tecnologias e ativos especializados (Featherstone \& Sherrick, 1992).

\subsection{O Papel do Governo Federal}

A participação direta do governo federal americano no mercado de crédito rural é limitada. Em 2002, o volume de recursos disponibilizados foi cerca de US\$7 bilhões, o equivalente a 3,5\% do total da dívida agrícola. Além disso, o volume de crédito rural oferecido através de programas do governo federal tem caído a cada ano desde 1985, quando atingiu o pico de US\$25 bilhões. Nos últimos 15 anos, a participação de mercado do governo caiu cerca de 13 pontos percentuais, de 16,3\% em 1986 para 3,5\% em 2002. 
O governo americano atua no mercado de crédito rural através de uma agência do Departamento de Agricultura (USDA) chamada Farm Service Agency (FSA). Atualmente, a FSA oferece cinco programas de crédito rural para produtores agrícolas através de empréstimos diretos ou garantias a empréstimos efetuados por intermediários financeiros. $\mathrm{O}$ foco destes programas são produtores jovens, que estão se iniciando na atividade agrícola, ou de baixa renda, os quais não conseguem financiamento através dos agentes privados por serem tomadores de alto risco. Por isso, a FSA é considerado um "lender of last resort".

Através de seus programas de garantia (Guaranteed Loan Program), a FSA garante até $95 \%$ do principal de empréstimos concedidos por outros agentes. A garantia da FSA normalmente resulta em termos de crédito mais favoráveis ao tomador, uma vez que o risco de inadimplência é efetivamente assumido pelo governo federal. Os programas de empréstimos diretos da FSA (Direct Loan Program) são destinados a produtores que não conseguem financiamento no mercado ou que são afetados por desastres naturais (empréstimos de emergência). Tanto os programas de garantia quanto os empréstimos diretos oferecem crédito operacional de curto prazo ou financiamento de longo prazo a taxas de juros abaixo das taxas correntes do mercado.

Além da atuação direta no mercado através dos programas da FSA, o governo federal tem relevante participação indireta no mercado de crédito rural. Por exemplo, em 1971 foi fundada a Federal Agricultural Mortgage Corporation, conhecida por Farmer Mac, uma agência privada patrocinada pelo governo federal que estabeleceu um mercado secundário para os empréstimos de longo prazo já concedidos a produtores, conectando os agentes financeiros servindo o mercado de crédito rural com o mercado de capitais em Wall Street. Apesar do sistema de crédito rural cooperativo (FCS) ser atualmente uma organização privada, a sua criação e financiamento inicial foi de responsabilidade direta do governo federal através de leis do congresso. Adicionalmente, o FCS é até hoje regulamentado por uma agência independente do governo federal, bem como os bancos comerciais e demais agentes financeiros. 
Outro ponto importante a ser realçado é o efeito indireto dos programas federais de política agrícola. A capacidade de repagamento das dívidas contraídas pelos produtores depende em parte dos programas de sustentação da renda agrícola. Destarte, a rentabilidade e a qualidade da carteira de crédito dos agentes financeiros atuando no mercado de crédito rural dependem indiretamente dos programas federais de política agrícola. Vale a pena lembrar que os agricultores americanos receberam em média US $\$ 8,8$ bilhões em pagamentos diretos do governo federal entre os anos 1990 e 1997, sendo que esta média aumentou para US\$15,1 bilhões entre 1998 e 2002 (USDA, 2003). O funcionamento adequado do mercado de crédito rural devese também à presença de programas de seguro agrícola, que afetam o risco de inadimplência do produtor. Sem o seguro agrícola, muitos produtores não teriam acesso ao mercado de crédito rural.

\section{Análise Comparativa dos Agentes Atuantes no Mercado de Crédito Agrícola}

A transferência de crédito nos EUA é efetuada por uma miríade de agentes públicos e privados com funções particulares no processo. O objetivo desta seção é fazer uma leitura do caso norte-americano com base no arcabouço teórico apresentado anteriormente, analisandose o potencial de cada agente em reduzir as fricções (os custos de informação e transação) que ocorrem no processo de intermediação financeira e transferência de crédito a produtores agrícolas.

Na Tabela 2, efetua-se uma análise qualitativa das vantagens comparativas de quatro tipos de agentes envolvidos no financiamento do setor agrícola - bancos comerciais, cooperativas de crédito, agentes privados dos SAGs (indústrias de insumos, cooperativas agrícolas, processadores, tradings, dentre outros) e programas governamentais na redução dos custos totais de fornecimento de crédito. Tais custos englobam a taxa de juros paga pelo emprestador, referente ao processo de captação de recursos financeiros utilizados nos empréstimos aos tomadores, à qual se adicionam custos de informação e transação na composição do custo final (taxa de juros) ao tomador. Com base na 
experiência norte-americana e nos conceitos teóricos discutidos na seção 2 deste trabalho, destaca-se qual tipo de agente tem maior importância relativa na redução de cada tipo de custo, conforme justificado a seguir.

Os bancos comerciais contam com depósitos de seus clientes e as cooperativas de crédito possuem uma corporação especializada na emissão de títulos de dívida como fontes principais de capital de risco. Portanto, tais "emprestadores tradicionais" possuem de forma geral fontes de recursos financeiros estáveis e relativamente baratas. Ao contrário, os agentes não-financeiros dos SAGs normalmente enfrentam maiores restrições na originação de recursos financeiros para oferecer crédito agrícola. Logo, devem utilizar fontes de recursos alternativas ou desenvolver novos mecanismos para financiamento de suas operações de crédito. De acordo com a pesquisa de Sherrick et al. (1994), a emissão de papéis comerciais, securitização de contas a receber e ativos líquidos da própria empresa e empresas coligadas são as principais fontes de recursos dos "emprestadores não-tradicionais".

\section{Tabela 2: Vantagens Comparativas de Diversos Agentes na Redução de Custos de Transferência de Crédito Agrícola nos EUA}

\begin{tabular}{|l|c|c|c|c|}
\hline \multicolumn{1}{|c|}{ Custo } & $\begin{array}{c}\text { Bancos } \\
\text { Comerciais }\end{array}$ & $\begin{array}{c}\text { Coopera- } \\
\text { tivas de } \\
\text { Crédito }\end{array}$ & $\begin{array}{c}\text { Agentes } \\
\text { dos SAGs }\end{array}$ & Governo \\
\hline Captação de Recursos & + & + & 0 & ++ \\
\hline Custos de Informação & 0 & ++ & ++ & 0 \\
\hline Custos de Transação Pré-Contratuais \\
\hline Negociação & + & ++ & ++ & 0 \\
\hline Salvaguardas & + & + & ++ & 0 \\
\hline Incentivos & 0 & ++ & ++ & 0 \\
\hline Custos de Transação Pós-Contratuais & ++ & ++ & 0 \\
\hline Monitoramento e Controle & + & + & ++ & 0 \\
\hline Má-adaptação & 0 & ++ & + \\
\hline
\end{tabular}

Legenda: + + = vantagem acentuada + + = vantagem moderada; $0=$ sem vantagem. 
Entretanto, são os programas governamentais de crédito agrícola que possuem as maiores vantagens de custo no que se refere à captação de recursos para empréstimos. De forma geral, tais programas podem captar recuros diretamente do tesouro nacional a custo marginal baixo ou por meio da emissão de títulos de dívida pública, os quais apresentam risco menor que os títulos emitidos por empresas privadas. Nos EUA, o governo federal também desempenha papel na captação de recursos de forma indireta, por meio de programas de estabilização da renda agrícola, que tendem a aumentar o fluxo de recursos para o setor agrícola como um todo, ou programas específicos de subsidíos ou redistribuição de renda, que favorecem determinados segmentos.

Dada a dispersão geográfica dos produtores agrícolas, os agentes que apresentam contato mais íntimo com o setor produtivo tendem a incorrer menores custos de obter informações sobre o perfil tecnológico e a reputação do produtor. Tais agentes são as cooperativas de crédito e os agentes não-financeiros atuando nos SAGs, tais como fornecedores de insumos e compradores de produtos agrícolas. Uma das vantagens do sistema de crédito cooperativo é justamente a presença de uma estrutura hierárquica de cooperativas locais e regionais que permite uma coleta e disseminação mais eficiente de informações geradas localmente. Uma vez que o tomador é também membro e proprietário da cooperativa, há incentivos adequados para o fornecimento de informações "sensíveis" para o emprestador, no caso a associação local de crédito. As empresas privadas dos SAGs, por sua vez, conhecem melhor a indústria onde operam e mantém relações comercias mais próximas e freqüentes com os produtores. Portanto, possuem também vantagens acentuadas na obtenção de informações para balizar a avaliação do risco de crédito de potenciais tomadores. Por não atuarem diretamente nos mercados agrícolas e não terem acesso a informações locais, bancos comerciais e agências públicas têm que gastar mais tempo e recursos na tentativa de reduzir a assimetria de informação com os produtores.

Adicionalmente, os agentes privados podem também ter um papel indireto na redução do custo de informação, por induzirem um processo de "auto-seleção" entre os tomadores (Staten et al., 1990). 
Isto ocorre em condições de informação assimétrica, onde os produtores diferem em termos de sua probabilidade de inadimplência e conhecem melhor esta probabilidade do que os emprestadores. Em geral, produtores honestos e com adequada sanidade financeira têm incentivos para se submeter a processos mais rigorosos e custosos de avaliação de crédito por parte de bancos comerciais, pois desta forma sinalizam sua "qualidade" e, conseqüientemente, podem obter taxas de juros mais baixas. Porém, não é lucrativo para produtores com alta probabilidade de inadimplência se submeter a processos rigorosos de avaliação de crédito, porque tais processos irão revelar sua baixa "qualidade". Estes últimos poderão, desta forma, se "auto-selecionar" para agentes não-financeiros com menores custos de empréstimo, como tende a ser o caso de agentes privados dos SAGs. Uma vez que os agentes não-financeiros almejam outros benefícios ao fornecer crédito, notadamente a venda de produtos ou serviços com alta margem de lucro aos tomadores, podem ofertar crédito mesmo quando tal atividade não é economicamente atrativa para agentes financeiros especializados.

As empresas privadas dos SAGs tendem a possuir maiores vantagens no processo de negociação, em particular com respeito aos custos para "juntar" emprestador e tomador. Uma vez que não necessitam investir em ativos fixos especializados - por exemplo, construções e equipamentos - existem substanciais economias de escopo na oferta de crédito em pontos-de-vendas (Henricksen \& Boehlje, 1995). Por outro lado, com respeito a salvaguardas contratuais, os bancos comerciais tendem a ser melhor capacitados na administração de procedimentos operacionais e na utilização de mecanismos padronizados de salvaguardas contratuais. Entretanto, os bancos podem ter desvantagens quando colaterais envolvem ativos mais específicos às partes envolvidas (Williamson, 1996). Por exemplo, o valor de uma trator usado para um fabricante de tratores é maior que para um banco que tem que executar legalmente um tomador inadimplente.

No caso de incentivos, as empresas dos SAGs tendem a possuir maiores vantagens comparativas, justamente porque os mecanismos mais poderosos para induzir o produtor a tomar medidas contra 
inadimplência são específicos à transação, em particular rendas adicionais com o contrato e transferência de tecnologia. Por exemplo, a Dole Foods, uma empresa norte-americana de comercialização de frutas, efetua contratos de aquisição com produtores e os auxilia no processo de captação de recursos, sinalizando ao sistema financeiro o seu perfil tecnológico como forma de auxiliar a avaliação do risco de crédito. No caso de hedging, a maior parte dos produtores não negocia diretamente em bolsas, mas indiretamente por meio de contratos a termo com cooperativas agrícolas, tradings e agroindústrias.

As cooperativas de crédito também possuem vantagens comparativas com relação a incentivos pré-contratuais na transferência de crédito, mas por razões diferentes dos demais agentes privados dos SAGs. Os produtores que formam uma cooperativa local para ter acesso a crédito também fazem parte de um grupo social. Desta forma, além dos incentivos propiciados pelo contrato formal de crédito, o comportamento do tomador passa a ser influenciado por suas relações inter-pessoais com os demais membros da associação. As interdependências entre membros de uma associação local de crédito são uma fonte de "capital social" (Putnam, 1993), um mecanismo de cumprimento informal de contratos que não está disponível aos demais agentes que participam do mercado de crédito agrícola. Por não terem acesso a mecanismos de incentivo além dos termos do contrato de crédito, os bancos comerciais e o governo estão menos capacitados que os agentes privados e as cooperativas de crédito na redução dos custos de transação pré-contratuais.

A vantagem comparativa de cooperativas de crédito e empresas dos SAGs é ainda mais acentuada no tocante a custos de transação pós-contratuais. Por estarem próximos do setor produtivo, tais agentes têm maior facilidade em monitorar se os recursos estão sendo aplicados conforme as cláusulas do contrato e se o desempenho dos produtores está sendo satisfatório. Os custos de acionamento de cláusulas contratuais e renegociação tendem também a ser menores, pois a maior freqüência de interação entre tais agentes e produtores tende a gerar maior flexibilidade para promover eventuais ajustes contratuais. Isto tende a reduzir a necessidade de gastos com litígio, 
os quais correspondem a uma parcela considerável dos custos de má-adaptação contratual.

No caso específico das cooperativas locais de crédito, o capital social formado pela rede de relações inter-pessoais entre membros também explica sua tendência em não agir oportunisticamente após a concretização do contrato. Isto ocorre porque a transação de crédito é apenas parte de um conjunto de laços sócio-econômicos com sua comunidade local. Sanções sociais tendem a reduzir os benefícios privados de se cometer ações oportunistas - por exemplo, tomar dinheiro e aplicar em ativos não especificados no contrato - facilitandose o cumprimento de tais contratos (Hoff \& Stiglitz, 1993). Portanto, a probabilidade de inadimplência e os custos de má-adaptação contratual tendem a ser reduzidos entre os membros de cooperativas locais de crédito.

Quanto às empresas privadas dos SAGs, um dos fatores que mais contribui para a redução dos custos de transação pós-contratuais é que a transferência de crédito tende a envolver contratos interligados - por exemplo, a venda de insumos ou contratos de aquisição futura de produtos (Bardham, 1989). Os contratos interligados possibilitam um controle contra ações oportunistas, porque a eventual quebra do contrato de crédito pode desencadear o término dos outros contratos. Além disso, a existência de um "pacote" de transações pode possibilitar o fornecimento de recursos na forma de produtos e serviços - por exemplo, fertilizantes ou defensivos - ao invés de dinheiro, o que ajuda a reduzir problemas de risco moral por parte do tomador. $\mathrm{O}$ fornecimento de insumos como forma de crédito é, portanto, uma forma de ajudar no cumprimento do contrato (Lazzarini, Neves \& Chaddad, 1999). Por este motivo, os bancos comerciais americanos tendem a oferecer crédito a menor custo ou termos contratuais menos restritos quando o produtor está associado contratualmente a uma empresa atuando nos SAGs.

Em suma, as cooperativas de crédito e as empresas que atuam nos SAGs apresentam elevadas vantagens comparativas no processo de aquisição de informações, negociação, estabelecimento de incentivos e gestão do processo pós-contratual em transações 
envolvendo crédito agrícola. Os bancos comerciais, por sua vez, têm maiores vantagens no processo de captação de recursos e no desenho de salvaguardas contratuais. Excetuando-se a sua posição favorável na originação de recursos, as vantagens do governo tendem a ser reduzidas e com feição mais indireta, por meio de políticas de estabilização da renda agrícola e programas de seguro rural. É importante ressaltar que o custo de captação de recursos pelos intermediários financeiros constitui somente uma parcela do custo total das transações de crédito. Ou seja, uma suposta vantagem comparativa de uma classe de emprestador na aquisição de capital de risco pode ser facilmente anulada por sua incapacidade de reduzir as fricções no processo de transferência de crédito.

A presente análise sugere que os diversos agentes envolvidos no financiamento do setor agrícola têm vantagens diferenciadas, que podem se auto-complementar. Sherrick (1998) relata que as empresas dos SAGs estão formando alianças estratégicas com os bancos comerciais e os bancos cooperativos a fim de aumentar a disponibilidade de recursos para seus programas de crédito aos produtores agrícolas. Percebe-se, então, que as empresas do agribusiness não competem diretamente com os "emprestadores tradicionais", mas sim aumentam a disponibilidade de crédito em determinados segmentos de mercado. Logo, há evidências de que se pode reduzir o custo e aumentar a disponibilidade de crédito caso aumente a participação dos agentes privados no mercado de crédito agrícola ou estes se alinhem estrategicamente com os emprestadores tradicionais.

\section{Considerações Finais}

O presente trabalho explora a idéia de que a disponibilidade e o custo de recursos financeiros para o financiamento da produção agrícola dependem não somente do custo de captação de recursos por intermediários financeiros, mas também de fricções que ocorrem no processo de transferência de crédito a tomadores. A partir do arcabouço conceitual acerca dos custos de informação e transação que emergem nos contratos de crédito, procurou-se realizar uma análise do mercado 
de crédito rural dos EUA, enfocando as vantagens comparativas dos diversos agentes que disponibilizam recursos financeiros para produtores agrícolas. De acordo com tal análise, os agentes nãofinanceiros atuando nos SAGs e as cooperativas de crédito agrícola apresentam substanciais vantagens comparativas na redução das fricções que ocorrem na transferência de crédito, enquanto os bancos comerciais e o governo conseguem originar recursos financeiros a menor custo relativo. $\mathrm{O}$ caso norte-americano é interessante, pois revela a importância econômica dos agentes privados no mercado de crédito agrícola e o potencial dos diversos agentes em combinar capacitações complementares a fim de se aumentar a eficiência do processo.

Entretanto, é importante apontar algumas limitações do presente estudo. A análise qualitativa apresentada na seção anterior aplica-se somente ao mercado norte-americano, uma vez que as vantagens comparativas dos agentes atuando no mercado de crédito agrícola são influenciadas pelo ambiente institucional e políticas públicas vigentes. Apesar dos agentes privados serem responsáveis por grande parcela da oferta de crédito rural nos EUA, a participação indireta do governo federal não deve ser negligenciada. Uma leitura cuidadosa do caso americano revela a importância de aspectos relacionados a direitos de propriedade bem definidos e à estabilidade macro-econômica naquele país. Portanto, generalizações para outros casos, incluindo-se o Brasil, devem ser feitas com cuidado.

Com estas limitações em mente, o presente trabalho pode servir de base para estudos mais detalhados sobre o mercado de crédito rural brasileiro. As idéias apresentadas aqui também sugerem potenciais avenidas para futuros trabalhos empíricos visando quantificar as diversas fricções no mercado de crédito e, principalmente, identificar quais agentes possuem maiores vantagens para reduzí-las. 


\section{Referências Bibliográficas}

AKERLOF, G. (1970). "The Market for Lemons: Qualitative Uncertainty and the Market Mechanism," Quarterly Journal of Economics 84(3): 488-500.

ARROW, K.J. (1971). Essays in the Theory of Risk-Bearing, Chicago: Markham Publishing Co.

BARDHAM, P. (1989). "A Note on Interlinked Rural Economic Arrangements," in Bardham, P. (editor), The Economic Theory of Agrarian Institutions, Oxford: Clarendon Press.

BARRY, P.J., BIERLEN, R.W. \& SOTOMAYOR, N.L. (2000). "Financial Structure of Farm Businesses under Imperfect Capital Markets," American Journal of Agricultural Economics 82(4): 920-33.

Cook, M.L. (1995). "The Future of U.S. Agricultural Cooperatives: A Neo-Institutional Approach," American Journal of Agricultural Economics 77(5): 1153-9.

COOK, M.L. \& CHADDAD, F.R. (2000). "Agroindustrialization of the Global Agrifood Economy: Bridging Development Economics and Agribusiness Research," Agricultural Economics 23(3): 207-218.

FEATHERSTONE, A.L. \& SHERRICK, B.J. (1992). "Financing Vertically Coordinated Agricultural Firms," American Journal of Agricultural Economics 74(5): 1232-37.

HENRICKSEN, W. \& BOEHLJE, M. (1995). "Captive Finance Companies: Are They Cost Competitive?" Journal of Agricultural Lending 9(2): 25-28.

HOFF, K. \& STIGLITZ, J.E. (1993). "Imperfect Information and Rural Credit Markets: Puzzles and Policy Perspectives," in K. Hoff, A. Braverman, \& J.E. Stiglitz (editors), The Economics of Rural Organization, Oxford: Oxford University Press.

KLEIN, B. (1996). "Why Holdups Occur: The Self-enforcing Range of Contractual Relationships," Economic Inquiry 34: 444-463.

KREPS, D.M., MILGROM, P., ROBERTS, J. \& WILSON, R. (1982). "Rational Cooperation in the Finetely Repeated Prisoners' Dilemma," Journal of Economic Theory 27: 245-252. 
LAZZARINI, S.G. (1998). "Harmonização do Fluxo de Capitais no Agribusiness," Revista de Política Agrícola 7(2): 26-27.

LAZZARINI, S.G. \& CHADDAD, F.R. (2000). "Finanças no Agribusiness," in D. Zylbersztajn and M.F. Neves (editores), Gestão e Economia dos Negócios Agroalimentares, São Paulo, SP: Editora Pioneira.

LAZZARINI, S.L., CHADDAD, F.R. \& COOK, M.L. (2001). "Integrating Supply Chain and Network Analysis: The Study of Netchains," Journal on Chain and Network Science 1(1): 7-22.

LAZZARINI, S.G., NEVES, M.F. \& CHADDAD, F.R. (1999). "Pacotes de Insumos Agrícolas: Mudando a Configuração do Agribusiness," Preços Agrícolas 13(154): 52-53.

MYERS, S.C. AND MAJLUF, N.S. (1984). "Corporate Financing and Investment Decisions When Firms Have Information That Investors Do Not Have," Journal of Financial Economics 13(2): 187-221. MYERSON, R.B. \& SATTERTHWAITE, M. (1983). "Efficient Mechanisms for Bilateral Trading," Journal of Economic Theory 29: 265-281.

PUTNAM, R.D. (1993). Making Democracy Work: Civic Traditions in Modern Italy. Princeton: Princeton University Press.

ROSS, S.A. (1973). "The Economic Theory of Agency: The Principal's Problem," American Economic Review 63(1): 134-9.

SAPPINGTON, D.M. (1991). "Incentives in Principal-Agent Relationships," Journal of Economic Perspectives 5(2): 45-66.

SHERRICK, B.J. (1998). "Emerging Nontraditional Lenders and Products," in Duncan, M. \& Stam, J.M. (editors), Financing Agriculture in the Twenty-First Century, Boulder, CO: Westview Press.

SHERRICK, B.J. \& Lubben, R.W. (1994). "Economic Motivations for Vendor Financing," Agricultural Finance Review 54: 120-31.

SHERRICK, B.J., SONKA, S. \& MONKE, J.D. (1994). "Nontraditional Lenders in Agricultural Credit Markets," Agribusiness 10(4): 341-57.

STATEN, M.E., GILLEY, O.W. \& UMBECK, J. (1990). "Information Costs and the Organization of Credit Markets: A Theory of Indirect Lending," Economic Inquiry 28: 508-29. 
STIGLITZ, J.E. (2000). "The Contributions of the Economics of Information to Twentieth Century Economics," Quarterly Journal of Economics 115(4): 1441-78.

STIGLITZ, J.E. (1974). "Incentives and Risk Sharing in Sharecropping," Review of Economic Studies 41: 219-55.

STIGLITZ, J.E. \& WEISS, A. (1981). "Credit Rationing in Markets with Imperfect Information," American Economic Review 71(3): 393-410.

U.S. DEPARTMENT OF AGRICULTURE (2003). Agricultural Income and Finance: Annual Lender Issue, Economic Research Service Report AIS-80, Washington, DC.

WILLIAMSON, O.E. (1996). The Mechanisms of Governance, New York: Oxford University Press.

WILLIAMSON, O.E. (1985). The Economic Institutions of Capitalism, New York: Free Press. 